\title{
Evaluation of Organic Camelina Crop Under Different Tillage Systems and Fertilization Types Using Proximal Remote Sensing
}

\author{
Foteini ANGELOPOULOU ${ }^{1 *}$, Evangelos ANASTASIOU ${ }^{2}$, Spyros FOUNTAS ${ }^{2}$ and Dimitrios BILALIS ${ }^{1}$ \\ ${ }^{1}$ Department of Crop Science, Laboratory of Agronomy, Agricultural University of Athens, 75 Iera Odos \\ Str., 11855 Athens, Greece \\ ${ }^{2}$ Department of Natural Resources Management \& Agricultural Engineering, Laboratory of Farm \\ Machinery, Agricultural University of Athens, 75 Iera Odos Str., 11855 Athens, Greece \\ *corresponding author: fangelo@aua.gr
}

BulletinUASVM Horticulture 77(1) / 2020

Print ISSN 1843-5254, Electronic ISSN 1843-5394

DOI:10.15835/buasvmcn-hort: 2019.0025

\begin{abstract}
A field experiment was conducted in Southern Greece to assess Normalized Difference Vegetation Index (NDVI) and Red-Edge Normalized Difference Vegetation Index (NDRE) in estimating Camelina's crop growth and yield parameters under different tillage systems (conventional and minimum tillage) and organic fertilization types (compost, vermicompost and untreated control). A proximal canopy sensor was used to measure the aforementioned Spectral Vegetation Indices (SVIs) at different days after sowing (DAS). Camelina presented the highest values of NDVI and NDRE under compost fertilization (0.63 and 0.22 accordingly) and minimum tillage system ( 0.50 and 0.18 accordingly). Additionally, the highest correlations between the measured crop parameters and NDVI, NDRE were achieved at leaf development to early flowering stage. Moreover, NDRE presented the highest correlation with seed yield $\left(\mathrm{R}^{2}=0.60, \mathrm{p}<0.05\right)$ and thus it is suggested for estimating Camelina's productivity instead of NDVI. Finally, further research is needed for adopting the use of remote sensing technologies on predicting Camelina's crop growth and yield.
\end{abstract}

Keywords: Camelina, compost, organic, remote sensing, tillage

\section{Introduction}

Camelina sativa (L.) Crantz is a cruciferous oilseed plant commonly known as Camelina, gold of pleasure or false flax, with a history of cultivation in Europe dating back to the Bronze Age (Bouby, 1998). Recently, C. sativa has been the subject of rekindled interest as a promising alternative oilseed crop with multitude potential applications in industry, cosmetics, human and animal nutrition, due to its unique seed quality and the several favorable agronomic traits. Camelina is identified as a short season crop, resistant to drought and low temperatures, compatible with reduced tillage and cover crops which can be grown on marginal soils and environmentally friendly with low input requirements (Putnam et al., 1993; Vollmann et al., 2007). Along with the fact that this crop has a considerably high seed oil content with an unusual fatty acid profile, rich in omega-3 fatty acids (Ibrahim and El Habbasha, 2015), suggests an ideal crop for sustainable agricultural systems and hence the need to optimize its production. This need can be achieved through the use of remote sensing methods, which can provide data that assess crop status, constituting an important tool to identify the limiting factors and the appropriate crop management strategies. 


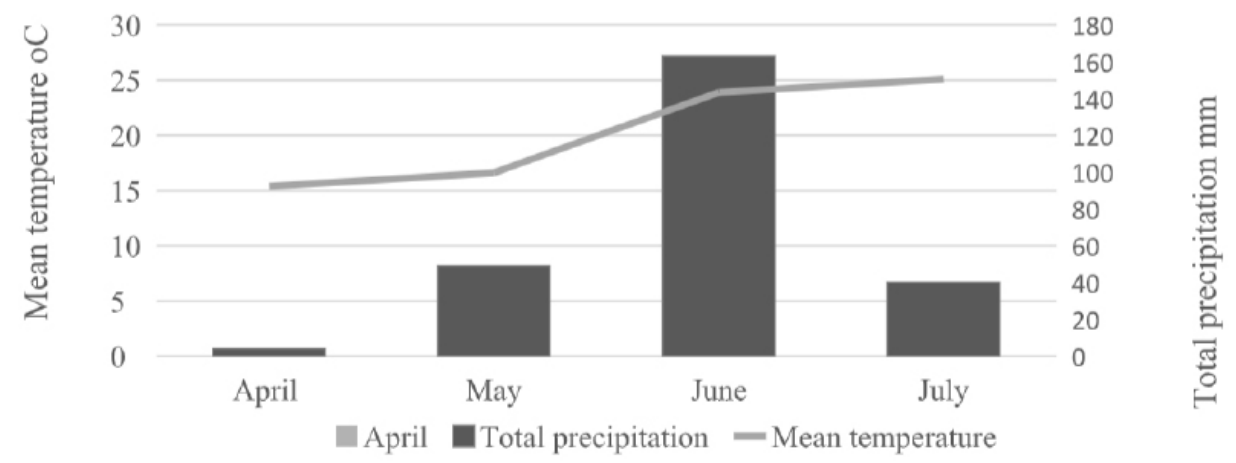

Figure 1. Meteorological data of the study site during the experimental period (April-July)

Table 1. Spectral vegetation indices

\begin{tabular}{ccc}
\hline Spectral Vegetation Index & Equation & Source \\
\hline NDVI & Rouse et al. (1973) \\
\hline NDRE & Gitelson and Merzlyak (1994) \\
\hline
\end{tabular}

Note. NDVI: Normalized Difference Vegetation Index; NDRE: Normalized Difference Red Edge Index; NIR: Near Infrared Band; RED: Red Band; RE: Red Edge Band.

Remote sensing (RS) can be defined as the art and science of collecting object or area related information from a distance without having direct physical contact (Shanmugapriya et al., 2019). In RS, spectral vegetation indices (SVIs) have been developed for assessing qualitatively and quantitatively vegetative covers by combining reflectance data from the electromagnetic spectrum (Bannari et al., 2009). Many researchers have used SVIs in various field crops (wheat, potato, rice, maize, faba bean, rape, sugarcane, sugar beet) to estimate crop status variables such as evapotranspiration, LAI, fraction of absorbed photo-synthetically active radiation, biomass, leaf nitrogen accumulation, and canopy cover (Travlos et al., 2017; Jin et al., 2018). The most commonly used quantitative index to assess the vegetation condition is the Normalized Difference Vegetation Index and was introduced by Rouse et al. (1973). Notwithstanding, NDVI tended to be saturated with increasing crop stand density and this raises the need to introduce new SVIs such as the Normalized Difference Red Edge (NDRE) to address this problem (Xie et al., 2018).

Despite the great interest in the implementation of RS methods in agriculture, research is still in its early stages for alternative oil seed crops such as Camelina. The aim of the study was to assess the effectiveness of different SVIs in predicting Camelina's growth and yield parameters, under different tillage systems and fertilization types.

\section{Materials and methods}

Site description and experimental details

A field experiment was carried out in Southern Greece $\left(37^{\circ} 30^{\prime} 30^{\prime \prime} \mathrm{N}, 22^{\circ} 22^{\prime} 30^{\prime \prime} \mathrm{E}\right.$; $660 \mathrm{~m}$ altitude, Tripoli region) in 2016 growing season. The soil of the study site was Clay Loam (Bouyoucos, 1962) and some of the initial soil chemical properties in the surface layer $(0-25$ $\mathrm{cm}$ ) were pH 6.5 (Bates, 1964), organic matter 1.58\% (Wakley and Black, 1934) and total nitrogen $0.10 \%$ (Bremmer, 1960). The monthly average temperature and total precipitation which were recorded at the experimental site during the experimental period (April-July) are presented in Figure 1. The experimental design was conducted under a split-plot experimental design with three replicates, two main plots and three sub-plots. Different tillage systems and organic fertilization types were assigned to the main plots and sub-plots, respectively. Regarding the tillage system, conventional tillage included moldboard plowing at $25 \mathrm{~cm}$ depth followed by one rotary hoeing, while the minimum tillage included the application of chisel plow at $15 \mathrm{~cm}$ depth followed by one rotary hoeing. Within each tillage treatment, the following fertilizer treatments were applied: i) vermicompost $\left(2 \mathrm{~N}-1.5 \mathrm{P}_{2} \mathrm{O}_{5}-1.5 \mathrm{~K}_{2} \mathrm{O}\right.$ 
Table 2. Effect of tillage system and organic fertilization types on NDVI and NDRE scores at different growth stages of Camelina

\begin{tabular}{|c|c|c|c|c|c|c|}
\hline \multirow[t]{2}{*}{$\begin{array}{c}\text { Fertilization } \\
(\mathrm{F})\end{array}$} & \multicolumn{3}{|c|}{ NDVI } & \multicolumn{3}{|c|}{ NDRE } \\
\hline & 30 DAS & $50 \mathrm{DAS}$ & 65 DAS & 30 DAS & $50 \mathrm{DAS}$ & 65 DAS \\
\hline Control & $0.18^{\mathrm{a}}$ & $0.25^{\mathrm{a}}$ & $0.32^{\mathrm{a}}$ & $0.08^{a}$ & $0.11^{\mathrm{a}}$ & $0.13^{\mathrm{a}}$ \\
\hline Vermicompost & $0.22^{\mathrm{a}}$ & $0.34^{\mathrm{a}}$ & $0.38^{\mathrm{a}}$ & $0.10^{\mathrm{a}}$ & $0.13^{\mathrm{a}}$ & $0.13^{\mathrm{a}}$ \\
\hline Compost & $0.31^{\mathrm{b}}$ & $0.63^{b}$ & $0.56^{\mathrm{b}}$ & $0.13^{b}$ & $0.22^{\mathrm{b}}$ & $0.18^{\mathrm{b}}$ \\
\hline Standard Error & 0.02 & 0.03 & 0.02 & 0.01 & 0.01 & 0.01 \\
\hline Tillage (T) & & & & & & \\
\hline Conventional & $0.20^{\mathrm{a}}$ & $0.31^{\mathrm{a}}$ & $0.31^{\mathrm{a}}$ & $0.09^{a}$ & $0.12^{\mathrm{a}}$ & $0.12^{\mathrm{a}}$ \\
\hline Minimum & $0.27^{b}$ & $0.50^{\mathrm{b}}$ & $0.53^{\mathrm{b}}$ & $0.12^{b}$ & $0.18^{\mathrm{b}}$ & $0.17^{\mathrm{b}}$ \\
\hline Standard Error & 0.01 & 0.02 & 0.02 & 0.01 & 0.01 & 0.01 \\
\hline $\begin{array}{c}\text { Interaction } \\
(\mathrm{F} \times \mathrm{T})\end{array}$ & NS & NS & $*$ & NS & $*$ & NS \\
\hline
\end{tabular}

Note: Means sharing different letters differ significantly at $P \leq 0.05$. NS: Not significant. *: Significant at $\mathrm{P}<0.05$.

$+52 \%$ organic matter); ii) compost $\left(7 \mathrm{~N}-4 \mathrm{P}_{2} \mathrm{O}_{5}-\right.$ $7 \mathrm{~K}_{2} \mathrm{O}+33 \%$ organic matter); and iii) control (no fertilization). Both organic fertilizers were applied at rates of $2000 \mathrm{~kg} \mathrm{ha}^{-1}$ before Camelina's sowing. The crop was sown at the middle of April, at a rate of $6 \mathrm{~kg} \mathrm{ha}^{-1}$, by hand in rows at $30 \mathrm{~cm}$ distance and drip irrigation was applied to cover crop water needs. The site was managed according to organic agricultural guidelines (EC834/2007).

\section{Data collection and analysis}

Data were collected both in the field and laboratory. Regarding the field measurements, a proximal canopy sensor RapidSCAN CS-45 (Holland Scientific, Lincoln, USA), which incorporates three lenses with different band absorption (Red at 670 $\mathrm{nm}$, Red Edge at $730 \mathrm{~nm}$ and Near Infrared at 780 $\mathrm{nm}$ ), was used for calculating NDVI and NDRE (Tab. 1).

NDVI is fundamentally a contrast between NIR light and Red light and its values range between -1 and +1 . While NDRE is a similar SVI to NDVI except its denominator incorporates a red edge band instead of red. The red edge band was found to present higher sensitivity compared to red band for assessing crop parameters. NDRE values also range from -1 to +1 , but in absolute form the values giving this index is lower than the NDVI. The actual range of NDRE in vegetation studies is usually from -0.1 to 0.3 . The sensor was held about $0.8 \mathrm{~m}$ above Camelina canopy and carried at a consistent speed to collect sensor's readings from six rows in each plot at 30, 50 and 65 days after sowing (DAS). The reflectance values were then averaged to represent reflectance for each plot.

Concerning the laboratory measurements, plant height and dry weight per plant were measured at ripening stage by sampling 10 plants from each plot. Dry weight was determined after drying for $72 \mathrm{~h}$ at $65^{\circ} \mathrm{C}$. At physiological maturity, number of siliques per plant in 10 plants from each plot while a total of 30 silicles from the abovementioned sample were used to measure the number of seeds per silicle. Finally, the seed yield was measured by weighing the Camelina seeds (seed moisture content 6-7\%) after harvesting each plot and cleaning the harvested seeds.

Data were subjected to statistical analysis according to split-plot design by using STATISTICA 7.0 software package. Specifically, the statistical analysis among the SVIs at different DAS and Camelina's crop growth and yield components included; Tukey's test to assess the difference between means, descriptive statistics, Pearson's correlation and regression model analysis for establishing linear regression models. The regression model analysis was performed only for the SVIs that presented the highest correlation for each approach and at a certain day after sowing.

\section{Results and discussions}

NDVI and NDRE variations across growth stages

The results showed that the effect of tillage system and organic fertilization type on NDVI and NDRE scores at different days after sowing (DAS) were statistically significant (Tab. 2). 
Table 3. Descriptive statistics of the proximal-based spectral vegetation indices at 30, 50, 65 DAS

\begin{tabular}{cccccc}
\hline & Min & Max & Mean & SD & CV \% \\
\hline NDVI 30 DAS & 0.14 & 0.41 & 0.24 & 0.08 & $33 \%$ \\
\hline NDRE 30 DAS & 0.07 & 0.17 & 0.10 & 0.03 & $26 \%$ \\
\hline NDVI 50 DAS & 0.17 & 0.79 & 0.41 & 0.20 & $50 \%$ \\
\hline NDRE 50 DAS & 0.08 & 0.27 & 0.15 & 0.06 & $38 \%$ \\
\hline NDVI 65 DAS & 0.24 & 0.73 & 0.42 & 0.16 & $38 \%$ \\
\hline NDRE 65 DAS & 0.10 & 0.23 & 0.15 & 0.04 & $26 \%$ \\
\hline
\end{tabular}

Note: SD: Standard Deviation, CV: Coefficient of Variance.

Table 4. Pearson correlation matrix for NDVI and NDRE in relation to crop components of Camelina sativa at $30,50,65$ DAS

\begin{tabular}{|c|c|c|c|c|c|c|}
\hline $\begin{array}{l}\text { Camelina yield and } \\
\text { yield components }\end{array}$ & NDVI & NDRE & NDVI & NDRE & NDVI & NDRE \\
\hline & \multicolumn{2}{|c|}{30 DAS } & \multicolumn{2}{|c|}{50 DAS } & \multicolumn{2}{|c|}{65 DAS } \\
\hline Plant height $(\mathrm{cm})$ & $0.94 * *$ & $0.93^{* *}$ & $0.90 * *$ & $0.88^{* *}$ & $0.89 * *$ & $0.82^{* *}$ \\
\hline Dry weight per plant (g) & $0.89 * *$ & $0.90^{* *}$ & $0.93 * *$ & $0.91^{* *}$ & $0.81^{* *}$ & $0.77^{* *}$ \\
\hline Number of silicles per plant & $0.81^{* *}$ & $0.83^{* *}$ & $0.90 * *$ & $0.89 * *$ & $0.79 * *$ & $0.76^{* *}$ \\
\hline Number of seeds per silicle & $0.71^{* *}$ & $0.72 * *$ & $0.72^{* *}$ & $0.67 * *$ & $0.60 * *$ & $0.54^{*}$ \\
\hline Seed yield (kg/ha) & $0.83^{* *}$ & $0.84 * *$ & $0.80 * *$ & $0.79 * *$ & $0.83^{* *}$ & $0.76 * *$ \\
\hline
\end{tabular}

Note: ${ }^{*}$ Correlation is significant at the 0.05 level. ${ }^{* *}$ Correlation is significant at the 0.01 level

The highest values of NDVI and NDRE at all DAS were observed under compost applications and minimum tillage system. On the contrary, the lowest values for both SVIs were recorded in unfertilized control and conventional tillage system. In addition, the temporal variability of both SVIs between the 30, 50 and 65 DAS provided information about the canopy level response that formed the foundation for assessing differences in crop growth and response to different practices applied. The outlying values can be explained by factors influencing the vegetation indices, such as dense of vegetation, stage of development or age of the plant, leaf colour and sensor imaging range (Carneiro et al., 2019). Furthermore, the interaction among tillage systems and organic fertilization types for NDVI was highly significant at ripening stage (65 DAS) while for NDRE was highly significant at flowering stage (50 DAS).

Spectral vegetation indices (SVIs) $\times$ Camelina yield and yield components

The SVIs displayed different coefficients of variance at DAS with NDVI presenting higher variability when compared to NDRE (Tab. 3). Specifically, the NDVI presented the highest CV at
50 DAS, which responds to early flowering stage, while the CVs of both SVIs presented lower at 30 and 65 DAS. These results are in agreement with Sulic and Long (2016) who referred that NDVI does not perform well during flowering, due to the fact that this SVI is an indicator of photosynthetic activity, which is decreased during this crop stage.

According to Pearson correlation analysis, the strongest correlations among the SVIs and the majority of the crop parameters were presented at 30 and 50 DAS (Tab. 4). Specifically, plant height and dry weight per plant presented the highest correlation values with vegetation indices when compared with the other parameters. This is in accordance with other studies in which canopy NDVI has been reported to present a significant positive relationship between plant height and crop yields (Yin and McClure, 2013; Zhou and Yin, 2014). Regarding the number of seeds per silicle, seed yield and number of silicles per plant, the highest correlations between these indices were achieved at 30 and 50 DAS respectively, mainly in the NDRE readings. Thus, given these results the most feasible period for assessing the crop growth would be between 30 and 50 DAS. These stages, leaf development until the beginning of flowering, 
Table 5. Regression models of the crop parameters with the highest correlated SVIs

\begin{tabular}{ccc}
\hline Regression Model & $\mathrm{R}^{2}$ & $\mathrm{RMSE}$ \\
\hline Plant height $(\mathrm{cm})=34.102+113.402 * \mathrm{NDVI}$ 30 DAS & 0.88 & \pm 2.8 \\
\hline Dry weight per plant $(\mathrm{g})=1.68615+8.34144^{*} \mathrm{NDVI}$ 50 DAS & 0.86 & \pm 0.6 \\
\hline Number of silicles per plant $=17.9306+452.493^{*}$ NDVI 50 DAS & 0.80 & \pm 35.9 \\
\hline Number of seeds per silicle $=4.45702+55.2266^{*}$ NDRE 30 DAS & 0.52 & \pm 1.1 \\
\hline Seed yield $(\mathrm{kg} / \mathrm{ha})=-29.6371+7889.19^{*}$ NDRE 30 DAS & 0.60 & \pm 131.1 \\
\hline
\end{tabular}

Note: $\mathrm{R}^{2}$ : Coefficient of Determination; RMSE: Root Mean Square Error.

have been reported to be more proper due to the contribution of yellow flowers on red light to a canopy-level signal and this added radiation reduces NDVI (Sulic and Long, 2016) and NDRE values. This is in agreement with Holzapfel et al. (2009) who found that NDVI presented higher correlations with seed yield at the same crop stages on Canola (relative crop to Camelina).

Based on the correlation analysis, regression models were built to associate SVIs with the measured crop parameters (Tab. 5). The data indicated that the simple regression models presented coefficients of determination that were ranging from 0.52 to 0.88 . The highest coefficient of determination was achieved for estimating the plant height through the use of NDVI at 30 DAS, while the lowest was achieved for estimating number of seeds per silicle. Seed yield estimation through the use of NDRE at 30 DAS presented coefficient of determination equal to 0.60 , suggesting that the specific SVI can be used as a moderate predictor at Camelina seed yield compared to NDVI.

\section{Conclusions}

This study constitutes a first approach regarding the use of remote sensing techniques in predicting Camelina's growth and yield performance. The results indicated that the highest values for both SVIs were obtained under compost fertilization and minimum tillage and consequently indicated that Camelina corresponds better under these treatments. Moreover, the best correlations among the evaluated crop characteristics and SVIs were obtained at leaf development and early flowering stages, and these should be considered as the optimal time for the monitoring of Camelina crop variability. Additionally, NDRE presented the highest correlation with seed yield and this SVI is recommended for estimating Camelina's yield. Nonetheless, further research is needed on assessing Camelina's growth and productivity under different treatments using remote sensing methods.

\section{References}

1. Bannari A, Morin D, Bonn F, Huete AR (1995). A review of vegetation indices. Remote Sensing Reviews, 13(1-2): 95-120.

2. Bates RG (1964). Determination of $\mathrm{pH}$. Theory and Practice. John Wiley and Sons, New York.

3. Bouby L (1998). Two early finds of gold-of-pleasure (Camelina sp.) in middle Neolithic and Chalcolithic sites in western France. Antiquity, 72: 391-398.

4. Bouyoucos GJ (1962). Hydrometer method improved for making particle size analyses of soils. Agronomy Journal, 54: 464-465.

5. Bremmer JM (1960). Determination of nitrogen in soil by Kjedahl method. Journal of Agricultural Science, 55:11-33.

6. Carneiro FM, Furlani CEA, Zerbato C, Menezes PC de, Silva Gírio LA da (2019). Correlations among vegetation indices and peanut traits during different crop development stages. Engenharia Agrícola, 39: 33-40.

7. Gitelson A, Merzlyak MN (1994). Spectral reflectance changes associated with autumn senescence of Aesculus hippocastanum L. and Acer platanoides L. leaves. Spectral features and relation to chlorophyll estimation. Journal of Plant Physiology, 143(3): 286-292.

8. Holzapfel CB, Lafond GP, Brandt SA, May WE, Johnston AM (2007). In-soil banded versus post-seeding liquid nitrogen applications in no-till spring wheat and canola. Canadian Journal of Plant Science, 87: 223-232.

9. Ibrahim FM, ElHabbasha SF (2015). Chemical composition, medicinal impacts and cultivation of camelina (Camelina sativa). International Journal PharmTech Research, 8:114-122.

10. Jin X, Kumar L, Li Z, Feng H, Xu X, Yang G, Wang J (2018). A review of data assimilation of remote sensing and crop models. European Journal of Agronomy, 92:141-152.

11. Putnam D, Budin J, Field L, Breene W (1993). Camelina: A promising low-input oilseed. New crops. Wiley, New York: 314-322.

12. Rouse J Jr, Haas RH, Schell JA, Deering DW (1974). Monitoring vegetation systems in the Great Plains with ERTS. In: Third earth resources technology 
satellite-1 symposium. National Aeronautics and Space Administration, 1: 309-330.

13. Shanmugapriya P, Rathika S, Ramesh T, Janaki P (2019). Applications of Remote Sensing in Agriculture - A Review. International Journal of Current Microbiology and Applied Sciences, 8(1): 2270-2283.

14. Sulik J, Long D (2016). Spectral considerations for modeling yield of canola. Remote Sensing of Environment, 184: 161-174.

15. Travlos I, Mikroulis A, Anastasiou E, Fountas S, Bilalis D, Tsiropoulos Z, Balafoutis A (2017). The use of RGB cameras in defining crop development in legumes. Advances in Animal Biosciences, 8(2): 224-228.

16. Vollmann J, Moritz T, Kargl C, Baumgartner S, Wagentristl $H$ (2007). Agronomic evaluation of camelina genotypes selected for seed quality characteristics. Industrial Crops and Products, 26: 270-277.
17. Wakley A, Black IA (1934). Estimation of soil organic carbon by the chromic acid titration method. Soil Science, 37: 29-38.

18. Xie Q Dash J, Huang W, Peng D, Qin Q, Mortimer H, Casa R, Pignatti S, Laneve G, Pascussi S, Dong Y, Ye H (2018). Vegetation indices combining the red and red-edge spectral information for leaf area index retrieval. IEEE Journal of selected topics in applied earth observations and remote sensing, 11(5): 1482-1493.

19. Yin X, McClure MA (2013). Relationship of Corn Yield, Biomass, and Leaf Nitrogen with Normalized Difference Vegetation Index and Plant Height. Agronomy Journal, 105: 1005-1016.

20. Zhou G, Yin X (2014). Relationship of cotton nitrogen and yield with Normalized Difference Vegetation Index and plant height. Nutrient Cycling in Agroecosystems, 100: 147-160. 